\title{
Identificando correntes teóricas de planejamento: uma avaliação do Plano Nacional de Saneamento Básico (Plansab)*
}

\author{
Rogério Braga Silveira \\ Centro Universitário de Belo Horizonte - UniBH \\ Léo Heller \\ Universidade Federal de Minas Gerais \\ Sonaly Rezende \\ Universidade Federal de Minas Gerais
}

O planejamento público no Brasil, em particular no campo do saneamento básico, vem se pautando por diferentes linhas teórico-metodológicas, nem sempre explícitas, sendo relevante um esforço de identificação das matrizes que estruturam o conteúdo dos diferentes planos desenvolvidos, uma vez que diferentes matrizes podem conduzir a diferentes implicações em sua implementação. Neste trabalho, avalia-se o Plano Nacional de Saneamento Básico (Plansab), utilizando, para tanto, um modelo de avaliação no qual se buscam identificar os princípios que fundamentaram sua elaboração, comparando-os com os valores defendidos por seis escolas de planejamento com destaque na atualidade. Foram priorizadas quatro categorias analíticas: metodologia, diagnóstico, participação da sociedade e visão de futuro. A comparação permitiu avaliar a coerência entre princípios que direcionaram a proposta inicial do planejamento e os realmente assumidos em cada uma das suas fases de elaboração, mostrando alinhamento do plano com correntes que preveem processo participativo, visão estratégica e visão de futuro capaz de lidar com incertezas.

Palavras-chave: Plansab; saneamento; planejamento; planejamento estratégico.

Identificación de las corrientes teóricas de planificación: una evaluación del Plan Nacional de Saneamiento (Plansab)

La planificación pública en Brasil, en particular la del sector de abastecimiento de agua y saneamiento, ha sido pautada por diferentes líneas teóricas y metodológicas, las cuales no siempre son explícitas. En vista de lo anterior, es importante realizar un esfuerzo para identificar las directrices que definieron el contenido de planes desarrollados, dado que diferentes fundamentos pueden conducir a diferentes implicaciones en su implementación. Este trabajo evalúa el Plan Nacional de Saneamiento Básico (Plansab), utilizando para este fin un modelo que permite identificar los principios que rigieron su

Artigo recebido em 4 jul. 2012 e aceito em 15 fev. 2013.

* Agradecemos a contribuição, na pesquisa e na análise dos dados que fundamentaram o presente trabalho, da doutoranda Severina Sarah Lisboa, bolsista da Capes, órgão ao qual somos também gratos. 
elaboración, los cuales fueron posteriormente comparados con valores defendidos por seis escuelas de planificación destacadas en la actualidad. Se utilizaron cuatro categorías analíticas: metodología, diagnóstico, participación de la sociedad y visión de futuro. La comparación permitió evaluar la coherencia entre los principios que originaron la propuesta inicial y aquellos realmente asumidos en cada una de las etapas de elaboración. Como resultado se encontró que el plan actual sigue líneas teóricas que integran procesos participativos, visión estratégica y prospección del futuro para enfrentar las incertidumbres.

Palabras clave: Plansab; agua; saneamiento; planificación; planificación estratégica.

Identifying theoretical tendencies of planning: an evaluation of the Plano Nacional de Saneamento Básico (Plansab)

Public planning in Brazil, particularly in the basic sanitation field, has been ruled by diverse theoretical-methodological approaches, not always explicit, while an effort on the identification of matrices which structure the content of the different developed plans is relevant, once different matrices may conduct to different implications during their implementation. In this article, the Plano Nacional de Saneamento Básico (Plansab) is assessed, using, for that, an assessment model in which it is aimed to identify the principles underlying the plan elaboration, comparing them with the values defended by six planning schools, prevailing currently. Four analytical categories were prioritized: methodology, diagnosis, society participation, and future vision. The comparison has allowed the evaluation of the coherence between the principles which directed the initial planning proposal and the ones which were really undertaken in each of the elaboration phases, showing alignment of the plan with lines of thought that advocate participative process, strategic view and future view capable of dealing with uncertainties.

Keywords: Plansab; water; sanitation; planning; strategic planning.

\section{Introdução}

O planejamento público no Brasil, em particular no campo do saneamento básico, vem se pautando por diferentes linhas teórico-metodológicas, nem sempre explícitas, sendo relevante um esforço de identificação das matrizes que estruturam o conteúdo dos diferentes planos desenvolvidos, uma vez que diferentes matrizes podem conduzir a diferentes implicações em sua implementação. O Plano Nacional de Saneamento Básico (Plansab) ${ }^{1}$ tem importância estratégica para o Brasil, ao disciplinar o processo de tomada de decisões na política pública setorial para os próximos 20 anos e ao se colocar como referência para os planos locais, a serem elaborados por determinação legal. Dessa forma, mostra-se relevante explorar os princípios adotados no referido plano, já que as visões de mundo que o sustentam serão determinantes no direcionamento de seus futuros programas e ações. Segundo Wack (1985:89), "estratégias

\footnotetext{
${ }^{1}$ Plansab. Disponível em: <www.cidades.gov.br/index.php/plano-nacional-de-saneamento-basicoplansab >. Acesso em: 18 fev. 2013.
} 
são um produto de uma visão de mundo. Quando o mundo se modifica, os gestores necessitam compartilhar uma visão comum desse novo mundo. De outra forma, decisões estratégicas fundamentadas com diferentes visões resultarão em anarquia". No âmbito deste estudo, o termo princípio é assumido segundo o entendimento de Cunha (2006:7), "como fator de existência, organização e funcionamento do sistema, que se irradia da sua estrutura para seus elementos, relações e funções. (...) A força do princípio se exerce na produção e estruturação do sistema, atuando como que como forma-matriz. (...) Ele pode ser explícito ou implícito".

Neste estudo, foi realizada uma avaliação do Plansab, com foco nos princípios sobre os quais foi estruturado, comparando-os com os valores característicos de correntes teóricas de planejamento com importante difusão no momento. Tal abordagem pretendeu verificar a coerência e a identificação de potenciais ameaças à sua implementação. Para o desenvolvimento da análise, os autores, que tiveram envolvimento em diferentes graus e níveis na elaboração do Plansab (Brasil, 2011a), procuraram se colocar, dentro do possível, distanciados do referido envolvimento no processo. Assim, foi desenvolvida uma releitura dos documentos, confrontando-os com as correntes mobilizadas e não com os pressupostos adotados originalmente.

O Plansab foi elaborado em três etapas. Na primeira formulou-se o Pacto pelo Saneamento Básico, que teve como finalidade buscar a adesão da sociedade aos eixos e estratégias de desenvolvimento do setor, bem como ao processo de elaboração e implementação do plano. Participaram dessa fase os segmentos da sociedade representados no Conselho das Cidades, que é composto por 71 representantes eleitos ou indicados por diferentes segmentos sociais (empresários, trabalhadores, acadêmicos, organizações não governamentais e poder público) e que tem, entre outras funções, a função de emitir orientações e fornecer informações, auxiliando no planejamento de desenvolvimento urbano. No Pacto pelo Saneamento Básico foram definidos como eixos básicos, com o objetivo de direcionar a elaboração do Plansab: universalização do acesso aos serviços, participação da sociedade, controle social, cooperação federativa, integração de políticas e sustentabilidade. Assim, o plano deveria ter sua centralidade no social (Brasil, 2008).

Na segunda etapa, a elaboração do Panorama do Saneamento Básico no Brasil compreendeu "ampla pesquisa, com sistematização e análise de informações, produção conceitual e desenvolvimento de prognósticos, contemplando": a definição de elementos conceituais, contextos e desafios que orientam a elaboração do Plansab; a análise situacional das condições do saneamento básico no país; a análise dos investimentos necessários para a concretização das metas propostas; a identificação das condições a serem enfrentadas e a formulação de uma visão estratégica para a política pública de saneamento básico no país para um horizonte de 20 anos; e a produção de cadernos temáticos, em número de 13, para o aprofundamento conceitual em assuntos de relevante interesse para as definições do Plansab (Brasil, 2011b:9).

A terceira etapa constitui-se de uma consulta pública, que submete a versão preliminar do plano, elaborada com base no Panorama do Saneamento Básico no Brasil, à sociedade, de modo a promover ampla discussão, com vistas à consolidação de sua forma final para posteriores encaminhamentos e execução (Brasil, 2011a). 
Como um de seus resultados, o Plano propõe a execução da política de saneamento básico no país com base em três programas: (i) Saneamento Básico Integrado, cujo objetivo é financiar as iniciativas de implantação de medidas estruturais, correspondendo aos tradicionais investimentos em obras, para a conformação das infraestruturas físicas, envolvendo os quatro componentes do saneamento básico - abastecimento de água, esgotamento sanitário, manejo de resíduos sólidos e manejo de águas pluviais; (ii) Saneamento Rural, destinado à população do campo e às populações tradicionais, visando à implantação de ações de infraestrutura e de medidas estruturantes, assumidas como aquelas que fornecem suporte político e gerencial para a sustentabilidade da prestação dos serviços, com base em metodologia envolvendo participação, educação ambiental e capacitação; Saneamento Estruturante, que tem por finalidade financiar medidas que visem à melhoria da gestão, da assistência técnica, da capacitação e das ações de desenvolvimento científico e tecnológico em saneamento, com ênfase na qualificação dos investimentos públicos (Brasil, 2011b).

\section{Métodos}

Os passos metodológicos que orientaram a presente análise seguiram as premissas básicas das técnicas empregadas em pesquisas qualitativas. O corpus da pesquisa é formado por dados provenientes de três abordagens principais, no que tange à coleta de dados: (i) documentos relacionados às etapas de elaboração do plano, representados por atas de reuniões, relatórios parciais e a proposta preliminar do plano; (ii) entrevistas com roteiro semiestruturado realizadas com atores de diferentes segmentos sociais que participaram da construção do plano; e (iii) observação participante nas reuniões e oficinas de discussão das premissas do plano. Com a primeira abordagem intentou-se aprofundar na caracterização dos aspectos de delineamento do Plansab, sua estrutura formal de desenvolvimento e encaminhamentos para sua forma final. As entrevistas, por sua vez, buscaram abarcar opiniões acerca dos valores que deveriam orientar um planejamento para o setor de saneamento. Com a observação participante foi possível captar a visão de especialistas e equipes do governo federal, no momento em que esses se dispuseram a pensar coletivamente os cenários de planejamento, compartilhando decisões estratégicas e validando as várias etapas intermediárias do trabalho.

O tratamento dos dados foi desenvolvido por meio da análise de conteúdo, seguindo os preceitos da análise de categorias, conforme modelagem sugerida por Bardin (2008). As proposições de Eisenhardt (1989), Yin (2004) e Coelho Cesar (2005) orientaram a escolha das quatro categorias analíticas utilizadas como referência no estudo, destacadas a seguir:

a) Metodologia. Procuram-se identificar as correntes de pensamento que deram sustentação às escolhas metodológicas adotadas, avaliando-se as opções realizadas.

b) Diagnóstico. Busca-se identificar a lógica presente na elaboração do diagnóstico, bem como o modo pelo qual essa escolha influenciou na elaboração do plano. 
c) Participação da sociedade. Verifica-se como se deu a contribuição dos atores sociais na elaboração do Plansab, bem como na apropriação de suas sugestões.

d) Visão de futuro. Identifica-se como foi estabelecida a visão de futuro, sendo avaliadas as possíveis consequências das escolhas realizadas sobre a implementação do plano.

As correntes teóricas de planejamento tomadas como referência são destacadas no item a seguir.

\section{Marco teórico}

Nesta seção, descrevem-se as características gerais de cada uma das seis correntes em discussão, no que dizem respeito aos elementos de maior interesse para a análise.

\subsection{0 planejamento tradicional}

O termo planejamento tradicional é utilizado por autores como Matus (1984), entre outros, para se referir ao modelo de planejamento normativo, desenvolvido no âmbito da Comissão Econômica para a América Latina e o Caribe (Cepal), a partir da segunda metade do século XX. A reforma social pode ser considerada a principal tradição dessa teoria do planejamento, tendo sido construída, ao longo do tempo, com a contribuição de inúmeros pensadores. Com Bentham, os reformistas sociais despertaram para a importância do estudo das consequências da ação e a avaliação dos seus custos e benefícios. Já Max Weber descreveu as características de uma sociedade racional acreditando que a ciência e a política deveriam ser mantidas, na prática, separadamente e, dessa forma, os cientistas produziriam conhecimento e os políticos produziriam as decisões políticas. Pensadores como Tugwell e Perloff teriam se destacado pela defesa do fortalecimento do Estado, de forma a se estabelecer uma inteligência institucionalizada, com o objetivo de orientar o futuro da coletividade. Os autores dessa tradição, de maneira geral, acreditavam que seria possível alcançar o interesse geral mediante o uso de instrumentos e técnicas de planejamento e assim este seria aceito pela maioria das pessoas de boa vontade. Nessa perspectiva, alguns autores como Mannheim e Etzioni acreditavam que o consenso poderia ser planejado. Eles consideravam o processo de formação do consenso como uma atividade centralizada e elitista (Friedmann, 1987:136).

Após a Segunda Guerra Mundial, Tugwell, Perloff, Banfield e Margolis participaram do programa de educação e pesquisa em planejamento, que viria a ser muito influente no direcionamento da teoria de planejamento da Universidade de Chicago. Foi criado então um modelo genérico para o planejamento, destinado aos países capitalistas democráticos, que incluía ideias das ciências sociais e econômicas. O modelo genérico de Banfield, rational planning (planejamento racional), tornou-se um guia para os planejadores e uma referência na abordagem de problemas na esfera pública, envolvendo (...) cinco passos, que mais tarde seriam 
descritos de forma simplificada como os cinco "D": "(...) desires, design, deduction, decision and deed" (desejos, projeto, dedução, decisão e ação) (Stiftel, 2000:6).

Na América Latina, a partir da década de 1960, o modelo normativo desenvolvimentista de planejamento foi eleito pela Cepal como o mais adequado para a superação dos problemas latino-americanos. Ainda hoje, os planejamentos governamentais no Brasil ou na América Latina são predominantemente normativos (Costa Filho, 2010:14).

O planejamento tradicional tem como uma de suas características a hegemonia da dimensão econômica, evidenciada no entendimento do planejamento como uma técnica que visa à racionalização e à otimização da aplicação de recursos, definindo seus objetivos e meios para alcançá-lo em função do custo/benefício econômico. Assim, considera o aspecto político como um dado exógeno, entendendo que a realidade apresenta comportamentos sociais estáveis e previsíveis, passíveis de serem estudados por meio de modelos analíticos. As metas são estabelecidas buscando-se uma situação de máxima racionalidade. O diagnóstico é feito a partir da análise do comportamento histórico, orientando-se, no entendimento dos planejadores, pela busca da verdade objetiva, científica. Na visão de futuro, o objeto do estudo é considerado estático e passivo, partindo-se do pressuposto de que o planejador tem todos os poderes e o objeto tende a se submeter às mudanças planejadas, e na análise da trajetória consideram-se os cenários tendenciais e normativos e admitindo-se trajetória única. O planejamento tradicional, segundo a literatura, seria vocacionado às instituições em que exista uma considerável concentração de poder e, portanto, não haja heterogeneidade de forças em disputa, além de um razoável consenso social (Giovanella, 1991; Rivera, 1992).

\subsection{0 planejamento estratégico situacional}

Carlos Matus, criador do planejamento estratégico situacional (PES), propõe que o planejamento público não seja privilégio de uma força social dominante e controladora circunstancial do Estado, entendendo que o ator que planeja está dentro da realidade e coexiste com outros atores sociais. Propõe a substituição das etapas sequenciais, presentes nos modelos tradicionais, por quatro momentos, dinâmicos, não excludentes, que nunca se esgotam e que devem ser reformulados durante todo o processo de vida do plano. No momento explicativo, equivalente ao diagnóstico, são apontados os problemas e discutidas suas causas, no nível dos fenômenos e das estruturas sociais básicas, produzindo explicação sistêmica da realidade; no momento normativo-prescritivo, é elaborado o desenho do "deve-ser"; no momento estratégico, trabalha-se com a ideia do "pode ser", privilegiando a análise e construção da viabilidade política; no momento tático-operacional, caracterizado pelo "fazer", ocorrem as tomadas de decisões e a realização da ação concreta (Rivera, 1992; Huertas, 1995).

Entre os fundamentos prescritos por Matus (1984:206) para elaboração de um planejamento destacam-se:

a) "planeja quem governa”, já que o governante é quem tem a capacidade de decisão e a responsabilidade de conduzir; 
b) "o planejamento refere-se ao presente", pois a simulação do futuro em um plano é somente um produto intermediário, que deve contribuir com a decisão a ser tomada no presente;

c) "o planejamento exige um cálculo situacional”, que considera como variáveis tanto a escassez de recursos quanto as dimensões sociais, políticas e administrativas;

d) "o planejamento refere-se a oportunidades e a problemas reais", uma vez que quem planeja deve buscar superar os obstáculos políticos, entendendo que existem atores que não comungam com a maneira de o planejador explicar a realidade, o que poderia provocar uma ação obstaculizadora e, assim, a visão desses atores deve ser entendida e considerada;

e) "o planejamento situacional é necessariamente político", uma vez que os limites da capacidade de produção de ações sociais estão vinculados às restrições de poder;

f) "o planejamento não é uma adivinhação do futuro", devendo-se, no entanto, considerar as possíveis incertezas que escapam ao desejo e controle de quem planeja e se desenvolver um planejamento e uma estratégia para os vários cenários que se viabilizem dentro dos extremos aparentemente possíveis: "é possível planejar ações, não para predizer o futuro, mas sim para criá-lo";

g) "o planejamento não é monopólio de quem planeja", devendo-se considerar que existem outros atores que também planejam com objetivos distintos, sendo indispensável prever suas resistências ativas e criativas.

Se, por um lado, essa corrente defende que o planejamento público seja um processo democrático, que reconheça a demanda que emerge da base social, por outro, afirma que o "máximo de liberdade é incompatível com o máximo de igualdade, sendo a reconciliação de ambos a função mais importante do planejamento" (Matus, 2000:219). Este autor chama a atenção para o fato de que a prática social horizontal no âmbito público atravessa várias disciplinas da ciência tradicional, produzindo problemas e gerando relações entre eles. Um projeto de governo deve responder aos problemas de forma intersetorial. Nessa perspectiva, segundo Costa (2004), o PES transcende um simples método de planejamento, apresentando-se como uma maneira de articulação governo-sociedade, desenhado como um instrumento de planejamento público e dirigido à alta direção dos governos.

\subsection{A prospectiva estratégica}

A prospectiva foi utilizada pela primeira vez na França, em 1970, em um estudo geográfico realizado pela Délégation à l'Aménagement du Territoire et à l'Action Régionale (Datar) (Godet, 1994). A prospectiva de primeira geração baseava-se na formalização matemática, na probabilidade e na investigação operacional, apoiando-se em métodos desenvolvidos por especialistas norte-americanos, que viriam a constituir um instrumental que incluía técnicas como análise estrutural, matriz de impactos cruzados e análises multicritério. Nos anos 1980, esse processo passou a 
ser utilizado em grandes empresas estatais e em diversos ministérios franceses, e, nesse período, a prospectiva se pôs a serviço da ação estratégica, o que levou Michel Godet a difundir o conceito de prospectiva-estratégica, apoiado na base conceitual da economia industrial e da estatística, constituindo-se, então, na segunda geração da prospectiva. A partir do final da década de 1990, iniciou-se a formação da terceira geração da prospectiva estratégica, que passou a incluir como questões centrais temas relativos ao território, desenvolvimento sustentável, governança, decisão pública e inteligência coletiva. Nessa nova fase, passou a sofrer significativa influência da ciência política, o que levou à criação de métodos com o objetivo de facilitar a participação da sociedade e o entendimento dos seus conflitos (Godet e Durance, 2007).

A escola de prospectiva estratégica entende que a complexidade dos problemas do cotidiano faz com que a elaboração de um plano exija a utilização de métodos tão rigorosos quanto participativos. Seu instrumental busca estimular a imaginação, reduzir as incoerências, criar uma linguagem comum, estruturar a reflexão coletiva e permitir a apropriação, respeitando-se a liberdade de escolha (Godet, 2006).

Para essa escola, deve-se evitar tanto pensar de cima para baixo, esquecendo-se da importância da apropriação, quanto afastar os peritos e as análises teóricas, para dar ouvidos somente à população. Entende que as decisões necessárias para fazer face aos desafios do futuro raramente são consensuais, afirmando, porém, que "é sempre uma má ideia querer impor uma boa ideia" (Godet e Durance, 2009:18). Assim, a prospectiva estratégica pode envolver tanto uma visão pré-ativa, preparando-se para as mudanças previsíveis, quanto uma visão proativa, agindo para provocar as mudanças desejadas, considerando-se que existem diversos futuros potenciais. A elaboração de um plano com essa metodologia pode requerer um prazo de até 18 meses (Godet e Durance, 2009).

A prospectiva estratégica apresenta uma primeira fase exploratória, envolvendo um expressivo número de atores, quando são identificados os desafios do futuro. Para tanto, são utilizados instrumentos da prospectiva para organizar e estruturar, de maneira transparente e eficaz, a reflexão coletiva. Na segunda fase, com caráter normativo, são feitas as escolhas estratégicas possíveis e desejáveis, por um limitado número de pessoas, em geral dirigentes (Godet et al., 2004).

\subsection{0 foresight}

O foresight pode ser entendido como um processo por meio do qual se busca chegar a uma compreensão das forças que moldam o futuro de longo prazo e que devem ser consideradas na formulação de políticas, no planejamento e na tomada de decisões (Coates, 1985). Em perspectiva similar, o foresight seria um processo de desenvolvimento de visões de possíveis caminhos, tendo-se em mente que as ações do presente contribuirão para a construção do futuro (Horton, 1999; Canongia, Santos e Zackiewicz, 2004). Pode ainda ser entendido como um processo que se ocupa sistematicamente de examinar o futuro de longo prazo da ciência, da tecnologia, da economia e da sociedade, com o objetivo de identificar as áreas de pesquisas 
estratégicas e as tecnologias emergentes que tenham a propensão de gerar os maiores benefícios econômicos e sociais (Maclean, Anderson e Martin, 1998).

Essa metodologia atua em três diferentes dimensões de um mesmo processo: pensar o futuro - os futuros possíveis são examinados a partir de tendências de longo prazo e especulações sobre fatos novos e inesperados; debater o futuro - o debate deve ter natureza participativa, requerendo o envolvimento de diferentes atores interessados; modelar o futuro - a identificação de futuros possíveis e desejáveis, além da interação e do aprendizado provocado nos participantes, potencializaria a tomada de decisões em diferentes níveis (Santos e Santos, 2003; European-Commission-Cordis, 2010).

Essa metodologia apresenta como características básicas (Kaivo-Oja e Marttinen, 2008; European-Commission, 2010):

a) ser orientada para a ação: pretende apoiar de maneira ativa os atores na sua construção, indo muito além de uma simples análise de futuro;

b) assumir diferentes alternativas para o futuro: o futuro não está predeterminado, podendo ser construído em diferentes direções, sendo possível ser, até certo ponto, influenciado pelos atores e pelas decisões tomadas no momento presente;

c) ser participativo: em seu processo de construção participam atores dos diversos segmentos da sociedade envolvidos com as questões em discussão;

d) ser multidisciplinar: as questões em foco são tratadas em sua totalidade, observando-se todas as variáveis que a influenciam, independentemente de serem qualitativas ou quantitativas.

Existem diversos modelos para a utilização da metodologia, em função da escolha da área a ser estudada, do tipo de atores envolvidos e da forma de interação e objeto do foco. Porém, todas as abordagens envolvem a antecipação (percepção), participação, networking, visão e ação (Keenan e Miles, 2002). Segundo Alvarenga e Soeiro de Carvalho (2007:17), o futuro parece apontar para uma passagem dos "métodos integrados proprietários a uma miscigenação de métodos e ferramentas, otimizando a sua integração em processos modulares e flexíveis em função de objetivos e necessidades específicas".

Com o objetivo de explorar novas possibilidades na estruturação, organização e gestão das atividades metodológicas, a European Foundation for the Improvement of Living and Working Conditions patrocinou a criação do projeto Euforia (Popper e Korte, 2004), que utiliza uma variedade de combinações de métodos foresight.

\subsection{A metodologia da Global Business Network (GBN)}

No início da década de 1970, Pierre Wack revolucionou a prospecção de cenários quando percebeu a necessidade de se criar uma nova ferramenta que auxiliasse no planejamento de longo prazo. Juntamente com a equipe de planejadores na Royal Dutch Shell, dedicou-se à 
pesquisa de eventuais fatores determinantes e seu possível impacto sobre o futuro daquela empresa, criando um novo conceito: o de planejar focando os cenários possíveis, metodologia esta que ficou conhecida como scenario planning. Esse instrumento permitiria adquirir maior compreensão do sistema em estudo, ao se identificarem os elementos predeterminados e se identificarem as conexões entre as várias forças e eventos que o conduzem, possibilitando uma decisão mais bem estruturada.

Em 1988, Peter Schwartz e Pierre Wack criaram a empresa de consultoria Global Business Network (GBN), popularizando o emprego dos cenários como instrumento de gestão estratégica (Moritz e Pereira, 2005). Essa escola entende o trabalho com cenários como mais uma arte que uma ciência, e seu processo de elaboração parte do específico para o geral. Levantam-se questões sobre quais decisões tomadas em uma organização terão influência, em longo prazo, no seu destino, para posterior construção do ambiente de planejamento. Para a GBN, os cenários assemelham-se a um conjunto de histórias construídas em torno de enredos que permitem destacar os elementos mais significativos. A metodologia prescreve a construção dos cenários em oito etapas: identificação da questão ou decisão central; identificação das forças-chave no ambiente local; identificação das forças motrizes; hierarquização dos fatoreschave e forças motrizes por importância e incerteza; seleção da lógica dos cenários; enriquecimento dos cenários; implicações; seleção dos indicadores (Schwartz, 2006).

O instrumental metodológico da GBN é considerado por Alvarenga e Soeiro de Carvalho (2007) como intuitivo, leve e pouco analítico, sendo muito utilizado por empresas que necessitam da elaboração de um plano em curto espaço de tempo e a baixo custo. Uma crítica a esse sistema, feita por Godet e Durance (2007), é de que sua replicação é difícil de ser conseguida, ficando o sucesso do plano dependendo da perícia do planejador.

\subsection{0 planejamento não euclidiano}

O planejamento não euclidiano, defendido por Friedmann (1992), é político por natureza; parte do princípio de que conhecimento e ação estão unidos; é orientado para o presente e se ocupa principalmente das mudanças institucionais e processuais de cada tema. Conta com a participação dos segmentos sociais, com o objetivo de construir um consenso entre os diversos atores, exigindo uma grande habilidade de negociação, de mediação e de comprometimento. Nesse modelo, é necessário que planejadores procedam cautelosa e experimentalmente à aprendizagem com os erros, permitindo uma retroalimentação da informação. Segundo o autor, o planejamento deve conter dois tipos de conhecimento: o dos experts e o experimentado (Friedmann, 1992).

O planejamento público nessa visão deve apontar as direções desejáveis de uma mudança social, que vise integrar as parcelas mais empobrecidas da população na sociedade. Essa integração deve se dar em três dimensões: política, favorecendo a reivindicação de uma democracia inclusiva, que busque alterar o sistema de relações políticas e as instituições correspondentes; econômica, procurando atender à reivindicação de um crescimento econômico 
adequado, que articule relações territoriais (políticas) e não territoriais (mercado); social, possibilitando atender reivindicações como as de igualdade, de gênero, culturais e de sustentabilidade ambiental (Friedmann, 1992).

Friedmann (2011) transcende a discussão que envolve o tema do planejamento, propondo uma nova visão de mundo, em que seja reconhecida a interdependência entre a racionalidade da motivação econômica e as relações morais, mas principalmente o espaço das pessoas na produção de suas próprias condições de sobrevivência. Dessa forma, o autor critica também a concepção burocrática de pobreza e os conceitos inerentes a ela, tais como linha de pobreza, pobreza absoluta e relativa e bolsões de pobreza, que tendem a tratar os pobres como incapazes de serem responsáveis por suas próprias vidas. Em seu entendimento, a abordagem da pobreza a partir da noção de necessidades básicas, na década de 1970, acabaria por levar planejadores a dilemas como:

a) desenvolvimento econômico versus redistribuição;

b) determinação tecnocrática versus determinação política das necessidades básicas;

c) produção versus consumo;

d) alocação via mercado versus alocação via planejamento.

Como uma alternativa, o autor propõe uma abordagem que veja a pobreza como uma forma de desempoderamento social, político e psicológico. Nesse contexto, a pobreza passaria a ser entendida de forma multidimensional, relacionada ao maior ou menor acesso que as famílias têm a cada uma das bases desse poder social, que envolve conhecimento, habilidades, nível de informação, organização social, recursos financeiros etc. A pobreza seria combatida, na medida em que fosse dado mais poder às famílias, para que pudessem assegurar um acesso maior a cada uma das dimensões do poder social, sendo necessária uma interação entre a economia de mercado e a sociedade civil (Friedmann, 1998, 2011).

\section{Resultados e discussão}

Nesta seção, é realizada a análise do Plansab, com foco nos princípios sobre os quais esse plano foi estruturado, cotejando-os com aqueles característicos das seis correntes teóricas de planejamento abordadas no marco teórico anteriormente descrito. O estudo abrange quatro categorias analíticas: metodologia; diagnóstico; participação da sociedade; visão de futuro.

\subsection{Metodologia}

Na metodologia adotada na elaboração do Plansab, observou-se o pressuposto de que o Brasil vive um momento democrático, com uma diversidade de forças sociais, eventualmente 
em disputa. Se, por um lado, persiste um considerável deficit social, por outro lado, cresce a consciência participativa da população, que vem conquistando, desde o restabelecimento do estado de direito, na década de 1980, espaços de participação para expressar suas demandas. Entendeu-se ainda que os problemas de saneamento, além de envolverem interesses de toda a população, dada a sua natureza, pedem por soluções intersetoriais, que perpassam as dimensões técnicas, de saúde, educacionais e ambientais, entre outras.

Essa visão limitou a adoção de métodos de natureza normativa, já que esses, por definição, seriam vocacionados para ambientes em que exista uma considerável concentração de poder e/ou um razoável consenso social. O respeito a uma sociedade plural e democrática determinou a escolha de um modelo com características participativas, que admitisse negociações e que, ao final, possibilitasse uma consistente visão social.

Entre as possibilidades teórico-metodológicas, o plano faz referências ao Planejamento Estratégico Situacional, à Prospectiva Estratégica, à metodologia da Global Business Network e ao foresight.

Embora se verifique alguma aderência entre o Plansab e a metodologia do PES, considerando que essa corrente transcende um simples método de planejamento, constituindo-se mais em uma forma de governo, e que o Plansab é um planejamento de longo prazo, envolvendo várias gestões governamentais, a proposta do Planejamento Estratégico Situacional não supriria integralmente as necessidades do plano. Essa opção é coerente com o que postulam autores como Rivera e Artmann (1999), de que o instrumental prospectivo do PES tem se mostrado insuficiente para responder a algumas necessidades, fazendo com que planejadores passem a recorrer a adaptações metodológicas, frequentemente buscando as técnicas prospectivas. Nos últimos anos, diversos planejamentos públicos brasileiros, tanto no nível federal, quanto no estadual, têm adotado métodos prospectivos que, de alguma forma, se fundamentam nas correntes de planejamento Prospectiva Estratégica, foresight ou GBN.

Na elaboração do Plansab, foi realizada a análise estrutural, que permitiu

a hierarquização das variáveis selecionadas (...); a análise de atores, visando à identificação da relação de força entre os atores; a avaliação da sustentação política dos cenários eleitos; e a análise morfológica, em que foram assumidas restrições para as combinações de hipóteses consideradas inconsistentes na conformação de cenários (...). (Brasil, 2011b:28)

A utilização desse instrumental revela uma opção por métodos formais e complexos, em direção diferente da dos métodos que prevalecem no modelo da GBN, que faz uma opção por métodos flexíveis e intuitivos, com mais difícil possibilidade de replicação. Comparando a metodologia adotada no Plansab com as preconizadas pelas correntes teóricas de planejamento, observa-se a opção pela utilização parcial de instrumentos formais e analíticos, como os indicados pela prospectiva estratégica, sugerindo que se buscou dessa forma superar os inconvenientes do pesado instrumental proposto por essa corrente, que seus próprios defen- 
sores admitem. Essa escola reconhece que o tempo é uma das principais limitações do método dos cenários por ela defendido:

São necessários, de um modo geral, de 12 a 18 meses para se percorrer o processo na sua totalidade, dos quais ao menos a metade se dedica à construção dos cenários da base. Se não for possível dispor mais do que de três a seis meses é preferível concentrar a realização do estudo nos módulos que pareçam mais importantes. (Godet e Durance, 2007:48)

Assim, o instrumental necessário para a aplicação dessa metodologia exigiria uma equipe de planejadores de grande porte, implicando também alto custo para a prospecção e análise, além de considerável tempo no desenvolvimento do planejamento.

Observa-se que no Plansab foram realizadas adaptações ao instrumental proposto pela prospectiva estratégica. Assim, na identificação das variáveis-chave ou na análise dos jogos de aliança e conflitos, instrumentos prescritos por essa corrente, como o Micmac e o Mactor, foram substituídos por planilhas específicas. Verifica-se uma opção pela mixagem de instrumentos na qual a prospectiva estratégica é mantida como eixo central, agregando-se a ela conceitos e instrumentos do PES, do foresight e da GBN. Observa-se também que foi aplicada a técnica de construção da "Visão", utilizada em planejamentos que se baseiam no foresight, que em um processo participativo pode facilitar que emerjam os desejos ou sonhos passíveis de serem alcançados, sendo estes muito úteis como direcionadores e motivadores dos debates. As adaptações metodológicas realizadas têm o potencial para resultar em considerável redução de recursos e tempo, em relação ao instrumental proposto pela prospectiva estratégica. Ainda assim, os instrumentos adotados têm características analíticas que possibilitam sua replicação, fatores esses que, em tese, são desejáveis em um planejamento nacional que pretende ser um norteador para planos locais.

A solução adotada no Plansab, a exemplo do projeto Euforia (Popper e Korte, 2004), acompanhou uma crescente tendência contemporânea, em que a preferência por métodos integrados e proprietários vem dando lugar a mixagens de técnicas e instrumentos, otimizando sua integração em processos modulares e flexíveis, em função das necessidades específicas. Baseando-se na proposta de Godet (2006), o plano foi estruturado em etapas não sequenciais, utilizando-se de seminários como um dos instrumentos para possibilitar a participação da sociedade em sua elaboração. Estes foram complementados por um conjunto de workshops e oficinas, alguns com especialistas e técnicos do governo e outros com participação mais plural, inclusive de representantes de entidades da sociedade civil, de prestadores de serviços e da iniciativa privada, o que se coaduna com o que prescreve a metodologia proposta por Godet (2006). Por outro lado, observou-se simplificação da modelagem de tratamento dos dados, na seleção dos condicionantes críticos, geradores dos cenários plausíveis. Dessa forma, em algumas etapas, foram utilizados métodos intuitivos, criados ou adaptados pela própria equipe de planejadores, cuja sustentação teórica é encontrada na GBN. 


\subsection{Diagnóstico}

O diagnóstico realizado no Plansab tem natureza situacional, envolvendo as dimensões deficit do saneamento básico, investimentos e ações realizadas pelo governo federal, além de uma avaliação político-institucional. Dessa forma, observa-se que, no plano, tal como prescreve a metodologia do PES, a situação é assumida como a arena onde se encontram os atores e suas ações, envolvendo também um cálculo complexo, que considera como variáveis tanto a escassez de recursos quanto as dimensões sociais, políticas e administrativas.

Na caracterização do deficit foram analisadas a infraestrutura implantada, os aspectos socioeconômicos e culturais, além da qualidade dos serviços ofertados, introduzindo-se os conceitos de atendimento adequado, precário ou inexistente. No diagnóstico político-institucional foram avaliados os fatores que contribuem para a constituição de padrões diferenciados de políticas e serviços de saneamento, nas diferentes regiões brasileiras. A análise baseou-se no princípio de que os programas e ações são produtos de um processo social complexo, influenciado por variáveis econômicas, políticas e ideológicas, expressando um determinado projeto político para a sociedade (Brasil, 2011a). Observa-se que o diagnóstico foi conduzido tomando como referência a proposta do planejamento estratégico situacional, onde o planejador deve entender o jogo social, identificando os atores relevantes. Diferentemente do planejamento tradicional, procurou-se transcender a simples descrição dos problemas, buscando-se uma explicação sistêmico-causal dos fatores que produziram os resultados sociais, estudandose a situação sanitária e sua relação com as condições sociais da população, as características de poder dos atores, as restrições legais, bem como as políticas setoriais. Aceitou-se, assim, a diferenciação entre os fatos políticos, econômicos e ideológicos, assumindo-se que esses aspectos não são isolados entre si, merecendo um tratamento sistêmico, em acordo com a proposta de Matus (1984, 2000).

Observa-se no plano que foram incorporadas, no diagnóstico, tanto a visão da sociedade, manifestada nos seminários regionais, quanto a dos especialistas, que produziram os estudos situacionais. O Plansab inovou conceitualmente o diagnóstico em saneamento, ao construir uma definição para deficit que contempla, "além da infraestrutura implantada, os aspectos socioeconômicos e culturais e, também, a qualidade dos serviços ofertados ou da solução empregada" (Brasil, 2011b:40).

Ao buscar as visões sistêmico-causais, tanto dos setores empresarial, quanto governamental, ou, ainda, dos movimentos populares, os planejadores admitiram que a explicação da realidade não necessita resultar em caracterização necessariamente homogênea, aceitando, em tese, o princípio defendido por Matus (1984) de que o planejamento não é monopólio de quem planeja. Destoa, assim, do planejamento tradicional, ao reconhecer não existir uma verdade única e objetiva, sendo possível, portanto, várias possibilidades de diagnóstico.

A análise desenvolvida a partir dos conceitos situacionais propostos no PES permitiu que fosse detectada a necessidade da implementação de medidas estruturantes e de programas específicos, direcionados às populações rurais e a comunidades tradicionais, como as indígenas e quilombolas. 


\subsection{Participação da sociedade}

Segundo o Pacto pelo saneamento básico: mais saúde, qualidade de vida e cidadania (Brasil, 2008), a elaboração do Plansab deveria ser pautada pela busca da adesão da sociedade, visando estabelecer o comprometimento dos segmentos da população interessados no tema com o plano. Em seu desenvolvimento, o plano percorreu diversos momentos que envolveram a participação da sociedade. Em toda a sua trajetória, sua elaboração foi acompanhada por dois grupos de trabalho: um composto por representantes das instituições públicas federais e outro constituído por representantes dos segmentos componentes do Conselho das Cidades. Essas instâncias participaram da definição das diretrizes básicas que orientaram a elaboração do plano e acompanharam suas diferentes etapas de desenvolvimento.

A construção dos três cenários de planejamento, um de referência e dois alternativos, contou com cinco seminários e workshops, envolvendo cerca de 600 participantes, com diferentes perfis e bastante representativos dos interessados no setor de saneamento. Além disso, foram realizados cinco seminários nas cinco macrorregiões do país, com a presença de 500 participantes, com representatividade semelhante à do Conselho das Cidades. Nestes, foram identificados 48 problemas que impediriam a universalização dos serviços de saneamento básico com qualidade, sendo também apresentadas 322 propostas para solucioná-los. Após produzida uma primeira versão do Plano, foram realizados cinco seminários regionais e duas audiências públicas para apresentação e discussão do planejamento pela sociedade. Finalmente, a versão resultante desse último processo foi submetida à consulta pública na rede mundial de computadores, tendo recebido 448 emendas após um período de 60 dias de consulta. Se, por um lado, esse processo participativo foi motivante para os atores envolvidos, por outro, apresentou limitaç̃es, já que as diferenças entre as visões de mundo dos participantes acabaram, em algumas situações, por gerar propostas antagônicas que se excluíam. Porém, de maneira geral, nos seminários regionais, ainda que existissem tais divergências, a dinâmica produzida foi suficiente para estimular as negociações dentro dos grupos de trabalho, fazendo com que as visões mais extremadas se submetessem a posições negociadas. As proposições buscavam obter a efetividade, dentro de uma perspectiva política, encampando a negociação e direcionando-a para soluções de problemas sociais, ambientais e econômicos, em sintonia com a proposta do planejamento não euclidiano (Friedmann, 1992). As entrevistas realizadas revelaram que os participantes dos seminários consideraram que essa fase prospectiva aumentou sua motivação e o comprometimento com o plano. Entretanto, se, por um lado, esse processo participativo foi motivador para os atores envolvidos, ele não se tornou completo, por si só, já que não é suficiente para se evitar a formulação de proposições contraditórias, fazendo com que a apropriação de umas, por parte dos planejadores, implicasse a eliminação de outras. Além disso, a falta de experiência na identificação de problemas, por parte de muitos dos atores, não permitiu, algumas vezes, o aprofundamento necessário na análise, prejudicando, em alguns casos, a qualidade das propostas. Esses problemas poderiam ter sido minimizados, caso o processo participativo tivesse seguido a sequência proposta pela prospectiva estratégica, que inclui uma melhor preparação dos participantes. Porém, a possível 
limitação de tempo e recursos financeiros teria implicado a necessidade de certa simplificação nessa fase participativa.

As decisões visando à superação dos desafios do futuro dificilmente são consensuais, sendo, portanto, necessária uma reflexão coletiva, onde haja a mais ampla participação da sociedade possível, de forma a permitir a apropriação das ideias e a busca do entendimento dos conflitos (Godet e Durance, 2009). Nessa perspectiva, observa-se que o Plansab foi elaborado de forma participativa, assumindo tanto as limitações, quanto a complexidade, bem como os riscos desse processo, superando a visão normativa presente no planejamento tradicional, em que a elaboração de um plano se circunscreve ao âmbito de quem planeja. Assim, seguindo as prescrições, tanto de Godet e Durance (2009) quanto de Friedmann (1992), o Plansab procurou manter o equilíbrio entre os saberes dos experts e o experimentado, tido como essencial para o sucesso de um planejamento. As entrevistas realizadas com os representantes sociais que participaram da construção do Plansab mostraram a existência de distintas visões de mundo e de organização do setor, que orbitam, de maneira geral, em torno de duas centralidades. Os atores do primeiro grupo assumem valores tais como a subordinação da sociedade às leis de mercado, com o interesse individual se sobrepondo ao coletivo. Defendem a participação do capital privado no saneamento, com base nas diversas modalidades sugeridas pelo Banco Mundial, mostrando preferência por aquela que, em cada caso, vier possibilitar maior lucro, com menor desgaste político. Para eles, é função do Estado regular e fiscalizar, de forma a garantir uma economia competitiva e inovadora. O planejamento público deveria ser negociado, possuindo, entretanto, um caráter técnico e tendo a busca pelo lucro como diretriz principal, pois somente assim se viabilizariam os investimentos no setor. Apesar de acreditarem que o saneamento deva ser completamente transferido para a iniciativa privada, passando a propriedade dos prestadores de serviços para o capital privado, percebem que não há, pelo menos no momento, condições políticas para que possam defender essa bandeira.

Na visão dos atores que compõem o segundo grupo, o saneamento básico é um direito humano, essencial, devendo seu provimento ser caracterizado como um serviço de natureza pública, o que permitiria que a população viesse a desfrutar das condições adequadas de saúde e qualidade de vida. Para eles, a discussão do tema saneamento deveria extrapolar o âmbito dos técnicos especializados, estabelecendo-se um processo participativo que envolveria pessoas com diferentes visões, em distintos lugares, e que propusesse ações que propiciassem a melhoria da qualidade de vida do segmento mais carente da população. Assim, o Estado deveria guardar uma autonomia, ainda que relativa, dos interesses do capital privado, impondo limites a esses, para que ocorra uma melhor alocação de recursos públicos em favor dos interesses da sociedade. Em sua concepção, o planejamento assumiria o conceito de que as necessidades sociais estão acima dos interesses individuais.

Nos seminários regionais, as propostas elaboradas nos grupos de trabalho foram, ao final, submetidas às seções plenárias e, mediante votação aberta, foram escolhidas as que deveriam ser sugeridas para a elaboração do Plansab. Observa-se que essas propostas mantinham sua centralidade no social. 


\subsection{Visão de futuro}

No Plansab partiu-se do princípio de que o futuro não seria simplesmente uma realidade desenhada pelos planejadores. Procuraram-se visualizar os futuros possíveis, levando-se em consideração as incertezas, com base na análise da situação atual e pregressa, admitindo-se, assim, que não seria razoável uma tentativa de predição do futuro, mas apenas de vislumbrar suas diversas possibilidades (Brasil, 2011b).

Observa-se no Plano a preocupação em desenvolver uma visão pré-ativa, com o objetivo de prepará-lo para as possibilidades do futuro, utilizando-se, para tanto, a técnica de cenários. Verifica-se, também, um comportamento proativo, visando influenciar na construção do futuro, através de seus programas, seguindo-se, dessa forma, a proposta da escola de prospectiva estratégica. Esse entendimento contrapõe-se ao modelo tradicional, em que a visão de futuro se limita à análise do comportamento histórico do objeto, da sucessão de conflitos, ou, ainda, da submissão do planejamento aos desejos dos seus planejadores.

Apesar de não negar a importância das ações dirigidas ao momento presente, o Plansab é apresentado como um planejamento de longo prazo, que pretende transcender os mandatos governamentais, incorporando em seus programas ações previstas para curto, médio e longo prazos. A visão de futuro adotada no plano diferencia-se, ainda que parcialmente, do entendimento de Friedmann (1992) ou de Matus (1984), que dão maior importância às ações proativas na linha temporal. Diferentemente do planejamento tradicional, que admite existir uma única trajetória plausível para o planejamento, e seguindo o pensamento da escola de prospectiva estratégica, assumiu-se que existem diferentes futuros potenciais, e a descrição dessas possibilidades deve instrumentalizar a elaboração das estratégias do planejamento.

Na etapa prospectiva do Plansab foram encontrados cerca de 40 mil cenários futuros potenciais e, com a utilização de instrumental técnico apropriado, esse número foi sendo reduzido. Ao final, restaram seis cenários, que vislumbravam desde futuros que apontavam para a expansão das políticas governamentais sociais, com o Estado assumindo papel de supridor dos serviços essenciais, até outro extremo, com a redução do tamanho do Estado, prevalecendo os valores econômicos sobre os sociais.

Um grupo de especialistas e autoridades públicas convidado a escolher, dentre os seis cenários, os três mais plausíveis, acabou por eleger os que mais privilegiariam os valores sociais. Os especialistas optaram por não assumir o entendimento do PES de que devem ser estudados os cenários que estão localizados dentro de extremos aparentemente possíveis. Concluíram eles que, embora possíveis, os cenários desconsiderados teriam baixa plausibilidade e, assim, não teria sentido assumi-los como integrantes do planejamento. Essa escolha é sustentada pela prospectiva estratégica, ao afirmar que um cenário não se constitui um fim em si, tendo seu estudo sentido somente se vier a produzir resultados, ou consequências para a ação. 


\section{Considerações finais}

A avaliação do planejamento, a partir da identificação dos princípios sobre os quais se estrutura, possibilitou que emergissem características do Plansab, como sua coerência, que tem o potencial de afetar seu sucesso ou fracasso. Isso porque, se os princípios assumidos em cada uma das fases de construção do plano forem conflitantes, o produto gerado será um planejamento desvirtuado de sua proposição inicial.

Os princípios contidos nos eixos básicos definidos para o Plansab, como universalização do acesso aos serviços, participação e controle social, cooperação federativa, integração de políticas e sustentabilidade, foram aceitos pelos atores sociais que participaram da elaboração do Pacto pelo Saneamento, independentemente de sua visão de mundo. Deve-se considerar, entretanto, que na fase inicial de elaboração de um planejamento as diretrizes ainda são postas de forma genérica e em alto nível de abstração. Não confrontá-las nessa fase pode se caracterizar como uma atitude politicamente adequada ao momento democrático em que vive o Brasil. As discordâncias emergem em fase posterior da elaboração do planejamento.

A escolha da metodologia foi um fator determinante para possibilitar a incorporação dos princípios definidos nos eixos básicos do plano. Observa-se que a opção por uma mixagem metodológica realizada é admitida e incentivada por autores do foresight, como Popper e Korte (2004). Assim, buscaram-se adotar princípios que estruturam o planejamento estratégico situacional, que trata o planejamento público sob uma ótica fundamentalmente política. A prospectiva estratégica norteou a estruturação metodológica do plano, bem como forneceu o instrumental analítico necessário à construção de cenários. A metodologia da GBN fundamentou as simplificações metodológicas utilizadas nas construções dos cenários e o foresight, também, permitiu a construção da "Visão" do plano. O mix metodológico adotado na construção do Plansab viabilizou a construção de um planejamento público participativo, que também se preocupou com a intersetorialidade, vislumbrando um horizonte de longo prazo que envolve vários mandatos governamentais, além de possibilitar a utilização de instrumentos analíticos e sua compatibilização com métodos intuitivos, quando necessários. Dessa forma, a construção metodológica utilizada para a elaboração do Plansab permitiu que fossem incorporados os princípios definidos em seus eixos básicos preliminares. No plano, optou-se por um diagnóstico de natureza situacional, incorporando-se diversas explicações da realidade e respeitandose o princípio da totalidade, segundo o qual não é possível uma desvinculação entre os fatos políticos, econômicos e sociais. Nessa perspectiva, o diagnóstico tornou-se fundamentalmente político, sendo estruturado tanto em indicadores de forma a incorporar um entendimento técnico, quanto por visões qualitativas, captadas por meio de um processo participativo que envolveu experts e demais atores sociais. Esse diagnóstico permitiu uma visão ampla dos problemas, possibilitando que fossem estruturadas soluções que envolveram áreas de interface com o saneamento, como a saúde e a educação.

O Plansab foi estruturado de forma a comportar uma elaboração participativa utilizando, para tanto, instrumentos como os seminários regionais, que ocorreram nas cinco macrorregiões do Brasil, na fase de elaboração, e audiências públicas posteriores, destinadas à sua 
discussão e validação. Embora nos seminários regionais tenha sido identificada a existência de atores sociais com diferentes visões de mundo, nas propostas aprovadas pelos participantes prevaleceram aquelas que possuíam uma visão social. Uma particularidade do Plansab que chama a atenção é a introdução da metodologia participativa em atividades que exigem especialização técnica. Assim, em diversos momentos do processo de elaboração foram realizados encontros com especialistas renomados em suas áreas de trabalho, não envolvidos diretamente com o plano, com o objetivo de apropriação de conhecimento. As entrevistas mostraram que o processo participativo foi motivante para os atores envolvidos. Conclui-se que a participação dos atores sociais no Plansab é coerente com os eixos básicos propostos, com a metodologia escolhida e com o modelo construído para o diagnóstico.

A história recente tem mostrado que o mundo moderno vive um período de significativa incerteza com relação ao futuro, já que as transformações de ordem política, econômica e social vêm acontecendo de forma intensa e em curtos períodos. Assim, passam a existir diversas possibilidades de futuro que nem sempre são as desejáveis pelos planejadores. Nesse contexto, elaborar um planejamento admitindo um único futuro plausível é um cálculo estratégico de alto risco. Na elaboração do Plansab, assumiram-se, como balizadoras das intervenções sobre a realidade, diversas possibilidades de futuro. Para estudá-las, optou-se pela técnica de prospecção de cenários. Nessa perspectiva, buscou-se desenvolver tanto uma visão pré-ativa, visando preparar o plano para diversas possibilidades de futuro, quanto uma visão proativa, com o objetivo de influenciar os acontecimentos futuros. A utilização de uma metodologia participativa na construção de diferentes cenários permitiu a incorporação de diferentes visões de futuro, oferecendo, portanto, um amplo leque de cenários futuros possíveis para a construção do planejamento. A visão de futuro baseada na construção de cenários comporta os princípios assumidos como eixos básicos, sendo também compatível com a metodologia eleita, com o modelo construído para o diagnóstico e com a elaboração participativa idealizada.

Este estudo de caso leva a algumas reflexões sobre a elaboração de um planejamento público:

a) Elemento importante no planejamento é a articulação entre a escolha da metodologia e a verificação a priori dos princípios assumidos em sua proposta inicial (no caso do Plansab seriam os eixos básicos), sob pena de um descompasso entre o que se pretende e o que se projeta.

b) A definição do modelo do diagnóstico pode mostrar a disposição dos planejadores em incorporar, ou não, os princípios mencionados na proposta inicial do plano.

c) A elaboração da visão de futuro pode ser considerada uma etapa inter-relacionada com o diagnóstico, já que ambas as fases têm por objetivo fornecer elementos que apoiarão o processo decisório sobre as ações a serem planejadas, sendo imprescindível haver coerência entre elas e entre os princípios assumidos.

d) A coerência entre as categorias analisadas possibilita que os princípios assumidos na proposta inicial direcionem de fato a elaboração do planejamento. De outra forma, quanto maior a distância entre esses e os valores apropriados em cada uma das fases, maior a pos- 
sibilidade de que o plano seja desviado de sua proposta inicial, fazendo com que esta seja transformada em apenas um discurso e o plano em um documento inerte e estanque.

\section{Referências}

ALVARENGA, António; SOEIRO DE CARVALHO, Paulo. A escola francesa de prospectiva no contexto dos futures studies: da comissão do ano 2000 às ferramentas de Michel Godet. Lisboa: Portugal, 2007.

BARDIN, Laurence. Análise do conteúdo. Lisboa: Prol, 2008.

BRASIL. Ministério das Cidades. Pacto pelo saneamento básico: mais saúde, qualidade de vida e cidadania. Brasília: Ministério das Cidades, 2008.

BRASIL. Ministério das Cidades. Panorama do saneamento básico no Brasil: elementos conceituais para o saneamento básico. Brasília: Ministério das Cidades, 2011a. v. I.

BRASIL. Ministério das Cidades. Panorama do saneamento básico no Brasil: visão estratégica para o futuro do saneamento básico no Brasil. Brasília: Ministério das Cidades, 2011b. v. VI.

CANONGIA, Claudia; SANTOS, Dalci; ZACKIEWICZ, Mauro. Foresight, inteligência competitiva e gestão do conhecimento: instrumentos para a gestão da inovação. Gestão \& Produção, s.1., v. 11, n. 2, p. 231-238, maio/ago. 2004.

COATES, Joseph. Foresight in federal government policy making. Futures Research Quartely, s.l., v. 1, n. 6, p. 29-53, Summer 1985.

COELHO CESAR, Ana Maria. Método do estudo de caso (case studies) ou método do caso (teaching cases): uma análise dos dois métodos no ensino e pesquisa em administração. São Paulo: Universidade Presbiteriana Mackenzie, 2005.

COSTA FILHO, Alfredo. Estado-nação e construção do futuro. Brasília: Cepal; Ipea, 2010.

COSTA, Hélio. Planejamento estratégico. Brasília: Ministério do Planejamento, Orçamento e Gestão, 2004.

CUNHA, Sérgio Sérvulo. Princípios constitucionais. São Paulo: Saraiva, 2006.

EISENHARDT, Kathleen. Building theory from case study research. Academy of Management Review, s.1., v. 2, n. 14, p. 532-550, Oct. 1989.

EUROPEAN-COMMISSION-CORDIS. What is foresight: definition. Disponível em:<www.cordis. lu/foresight/definition.htm>. Acesso em: 30 abr. 2010.

EUROPEAN-COMMISSION. Characteristics of foresight. Disponível em: < http: //forlearn.jrc. ec.europa.eu>. Acesso em: 20 abr. 2010.

FRIEDMANN, John. Empowerment: the politics of alternative development. Oxford: Blackwell, 1998. 
FRIEDMANN, John. Planificación para el siglo XXI: el desafío del postmodernismo. Eure, s.l., v. XVIII, n. 55, p. 79-89, nov. 1992.

FRIEDMANN, John. Planning in the public domain: from knowledge to action. Princeton: Princeton University Press, 1987.

FRIEDMANN, John. Insurgencies: essays in planning theory. Londres: Routledge, 2011.

GIOVANELLA, Lígia. As origens e as correntes atuais do enfoque estratégico em planejamento de saúde na América Latina. Cadernos de Saúde Pública, s.1., v. 7, n. 1, p. 26-44, 1991.

GODET, Michel. Creating futures scenario planning as a strategic management tool. Paris: Economica, 2006.

GODET, Michel. From anticipation to action: a handbook of stratégie prospective. Paris: Unesco, 1994.

GODET, Michel; DURANCE, Philippe. La prospectiva estratégica para las empresas y los territorios. Paris: Lipsor, 2009.

GODET, Michel; DURANCE, Philippe. Prospectiva estratégica: problemas y métodos. 2. ed. Paris: Lipsor, 2007.

GODET, Michel et al. Scenarios and strategies. A toolbox for problem solving. Paris: Lipsor, 2004.

HORTON, Averil. A simple guide to sucessful foresight. Foresight, s.1., v. 1, n. 1, p. 5-9, Feb. 1999.

HUERTAS, Franco. O método PES: entrevista com Matus. São Paulo: Fundap, 1995.

KAIVO-OJA, Jari; MARTTINEN, Jouni. Foresight systems and core activities at national and regional levels in Finland 1990/2008: developing foresight systems for a better life in Finland and Europe. Helsinki: Finland Futures Research Centre, 2008.

KEENAN, Michael; MILES, Ian. Practical guide to regional foresight in the United Kingdom. Oxford: Prest; University of Manchester, 2002.

MACLEAN, Marlie; ANDERSON, Joe; MARTIN, Ben R. Identifying research priorities in public sector funding agencies: mapping scienceoutputs on to user needs. Technology Analysis and Strategic Management, s.l., v. 10, n. 2, p. 139-155, June 1998.

MATUS, Carlos. Teoria del juego social. Caracas: Fondo Editorial Altadir, 2000.

MATUS, Carlos. Planificación, liberdad y conflito. In: ARGENTINA. Evaluación y uso de la información: manual de estrategias para el uso e incorporación de la información de evaluación. Buenos Aires, 1984. p. 198-225.

MORITZ, Gilberto; PEREIRA, Maurício. Planejamento de cenários: a evolução do pensamento prospectivo. Revista de Ciências da Administração, s.1., v. 7, n. 13, p. 1-20, jan./jul. 2005.

POPPER, Rafael; KORTE, Werner. Xtreme Euforia: combining foresight methods. In: EU-US SEMINAR: NEW TECHNOLOGY FORESIGHT, FORECASTING \& ASSESSMENT METHODS, 13-14 may 
2004. p. 1-30. Disponível em:<http://foresight.jrc.ec.europa.eu /fta/papers/Session\%203\%20M odels\%20and\%20Voices/Xtreme\%20EUFORIA.pdf>. Acesso em: 30 set. 2009.

RIVERA, Uribe. Planejamento e programação em saúde: um enfoque estratégico. São Paulo: Cortez, 1992.

RIVERA, Uribe; ARTMANN, Elizabeth. Planejamento e gestão em saúde: flexibilidade metodológica e agir comunicativo. Ciência \& Saúde Coletiva, s.1., v. 4, n. 2, p. 355-365, 1999.

SANTOS, Dalci; SANTOS, Marcio. A atividade de foresight e a União Europeia. Parcerias estratégicas, s.1., v. 8, n. 17, p. 165-191, set. 2003.

SCHWARTZ, Peter. A arte da visão de longo prazo. Rio de Janeiro: Best Seller, 2006.

STIFTEL, Bruce. Planning theory. The National AICP Exam preparation course guidebook. Washington, DC: American Institute of Certified Planners, 2000. p. 4-16.

WACK, Pierre. Scenarios: shooting the rapids. Harvard Business Review, s.1., v. 5, n. 63, p. 139-150, Nov./Dec. 1985.

YIN, Robert. Estudo de caso: planejamento e métodos. Porto Alegre: Bookman, 2004.

Rogério Braga Silveira é doutor em saneamento, meio ambiente e recursos hídricos e professor do Centro Universitário de Belo Horizonte (UniBH). Engenheiro eletricista, especialista em gestão estratégica, especialista em políticas públicas e mestre em administração pública. E-mail: rogesilbr@gmail.com.

Léo Heller é doutor em epidemiologia e professor titular do Departamento de Engenharia Sanitária e Ambiental da Universidade Federal de Minas Gerais (UFMG). Engenheiro civil, especialista e mestre em engenharia sanitária.E-mail: heller@desa.ufmg.br.

Sonaly Rezende é doutora em demografia e professora adjunta do Departamento de Engenharia Sanitária e Ambiental da Universidade Federal de Minas Gerais (UFMG). Engenheira civil e mestre em engenharia sanitária. E-mail: srezende@desa.ufmg.br. 